\title{
The use of an educational tool to improve adjustment to the sepsis protocol and the clinical impact
}

\begin{abstract}
Introduction: Sepsis is a major global health problem and is responsible for the deaths of thousands of people each year. It is the second leading cause of death in intensive care units, after coronary heart disease. Due to the high mortality rate, sepsis needs to be addressed through evidence-based practice, institutionalized protocols, well-developed clinical strategies, and continuing education. This study analyzed the clinical impact of adherence to an education tool for sepsis control measures at the Adventist Hospital of Belém in Brazil.
\end{abstract}

Methodology: A prospective, quasi-experimental study was carried out from March to December 2015. The study included 152 patients diagnosed as having selection criteria with suspected sepsis. The patients diagnosed in the emergency department of the hospital were divided into a control group $(n=30)$ and a case group $(n=122)$ based on the period in which an educational tool was applied, for adherence to the hospital sepsis protocol.

Results: The best adherence measure, after the tool application, was antimicrobial therapy. There was a reduction in the hospitalization time of the surviving patients from 19.7 days to 7.7 days and the mortality rate decreased from $63.3 \%$ to $30.6 \%$.

Conclusion: Although adherence to resuscitation packages was low, the education tool increased the insight of professionals in the identification of septic patients, resulting in a diagnosis and early treatment that corresponded with a reduction in hospitalization time and a decrease in mortality.

Keywords: sepsis, formative feedback, hospital mortality, antibiotics, sepsis protocol
Volume 2 Issue 6 - 2017

\begin{abstract}
Adriana de Oliveira Lameira Veríssimo, Edgar de Brito Sobrinho, Fabiana do Socorro da Silva Dias de Andrade, Fabianne de Jesus Dias de Sousa, Talita da Silva Gomes, Milene Gouvêa Tyll, Milce Ellen Barros de Oliveira Physiotherapist, Hospital Adventista de Belém, Brazil
\end{abstract}

Correspondence: Fabianne de Jesus Dias de Sousa, Physiotherapist, Hospital Adventista de Belém, Brazil, Email fabiannesousa@hotmail.com

Received: May 15, 2017 | Published: May 24, 2017

\section{Introduction}

Sepsis is a major global health problem that affects millions of people every year, leading to the death of one in four people. The incidence of sepsis has increased over time..$^{1-3}$ In the United States, there has been an average annual incidence of 300 cases per 100,000 inhabitants, an increase of $13 \%$ per year, and mortality ranges from $14.7 \%$ to $29.9 \%{ }^{3}$ Recently, a study conducted to compare sepsis care in the United States and Europe found that the gross hospital mortality rate associated with sepsis in Europe is $41 \%{ }^{4}$ In Brazil, mortality is $50-60 \%$, which is considered among the highest in the world. ${ }^{5}$ The SPREAD study, which randomized 231 intensive care units (ICUs) in Brazil, revealed that $30 \%$ of the ICU beds in the country were occupied by patients with severe sepsis or septic shock, and $55 \%$ of these patients died. ${ }^{6}$

Sepsis is the second main cause of death in ICUs, after coronary diseases, accounting for $20 \%$ of the admissions. ${ }^{7}$ Although there has been advancement in medical science, both in technology and in therapeutic measures such as the appearance of antibiotics, the mortality of these patients remains high. ${ }^{8}$ Due to the seriousness of the problem, the Surviving Sepsis Campaign (CSS) was launched in 2002, where it was recommended that institutions have strategies for detecting sepsis and that they institute update programs to improve care. Evidence shows that the effective implementation of protocols has an impact on the survival of patients. ${ }^{9}$ The establishment of protocols in the medical services is an excellent strategy to reduce sepsis since these protocols aim to diagnose in a shorter period of time and treat the disease in a more effective way, according to the needs of individual patients. ${ }^{10}$

Studies show that the early implementation of measures to combat sepsis ensures interventions at each stage, allowing the application of strategies to improve therapy. Considering the great importance of protocols, this study aimed to analyze the clinical impact of the use of an education tool in the adherence to the sepsis protocol. Additionally, the study sought to identify the measures with better adherence after the implementation of the tool and to analyze the length of hospitalization and mortality before and after implementation of the tool.

\section{Materials and methods}

This was a prospective, quasi-experimental study conducted from March to December 2015 in a private, tertiary hospital, a reference center for highly complex cases. The implementation of a health education tool in the sepsis protocol was evaluated. The implementation of the protocol took place in the March 2015. During this process, reference guides were developed and explanatory leaflets and flowcharts with algorithms were distributed throughout the hospital, mainly in the emergency department. The guides were based on the international guidelines of Sepsis and the Brazilian Patient Safety Program. ${ }^{1,9-16}$ 
The implementation of the educational tool and feedback letter was performed in August 2015. Patients admitted from March to July 2015 , the period prior to the use of the tool, were eligible for participation in the control group, while patients admitted from August to December 2015 were eligible for participation in the case group. All adult patients greater than 18 years of age and diagnosed with sepsis, severe sepsis, and septic shock, admitted from the emergency department or transferred to the ICU within the first 24 hours of the diagnosis, were included in the study. The criteria for defining sepsis were based on the Sepsis Survival campaign (CSS) criteria. Obstetric patients, patients with sepsis referred from other institutions, and patients with organic dysfunctions not considered secondary to a chronic disease were excluded.

The compilation of clinical and demographic data was conducted through the patients' clinical histories, using the form designed by the Institute Latin American Sepsis (ILAS) ${ }^{9}$ and adapted by hospital quality management in conjunction with the Hospital Infection Control Committee $(\mathrm{CCIH})$. From the time that the patient with suspected sepsis was admitted to the hospital, the CCIH team was activated and the data was collected using the pre-designed form. The evaluation was based on compliance with the updated CSS resuscitation package from 2012. The package also includes requirements that must be met within the first three and six hours, which are comprised of diagnostic and therapeutic interventions. The measures were considered adherent to the protocol when they complied with each item of the package Table 1. Once the evaluation of compliance with the protocol was made, a letter of feedback was sent to the professionals who attended the patient at the time of the suspicion of sepsis, indicating adherence to the measures. Patients were followed up until hospital discharge to determine their vital status.

Table I Surviving sepsis campaign therapy packs'

\begin{tabular}{|c|c|}
\hline S. no & 3 Hour packages \\
\hline I & Measure the lactate level. \\
\hline 2 & Obtain blood cultures before administration of antibiotics. \\
\hline 3 & $\begin{array}{l}\text { Initiation of broad-spectrum antibiotics intravenously within the } \\
\text { first hour of diagnosis. }\end{array}$ \\
\hline \multirow[t]{2}{*}{4} & $\begin{array}{l}\text { Administer } 30 \mathrm{~mL} / \mathrm{kg} \text { of crystalloids or the equivalent of colloids } \\
\text { for hypotension or lactate } \geq 4 \text {. }\end{array}$ \\
\hline & $\begin{array}{l}6 \text { Hour packages (Patients with hyperlactatemia or } \\
\text { persistent hypotension }\end{array}$ \\
\hline I & $\begin{array}{l}\text { Apply vasopressors (for hypotension that does not respond to } \\
\text { initial resuscitation of liquid to maintain a PAM } \geq 65 \mathrm{mmHg} \text { ). }\end{array}$ \\
\hline \multirow[t]{4}{*}{2} & $\begin{array}{l}\text { In case of persistent hypotension despite resuscitation of initial } \\
\text { volume or lactate of } 4 \mathrm{mmol} / \mathrm{L}(36 \mathrm{mg} / \mathrm{dL}) \text { : }\end{array}$ \\
\hline & - Measure central venous pressure (CVP) \\
\hline & - Measure central venous oxygen saturation (ScrO2) \\
\hline & - Measure the lactate again \\
\hline
\end{tabular}

'Sepsis survival campaign: International guidelines for the treatment of severe sepsis and septic shock (20I2). PAM, mean arterial pressure.

\section{Ethical aspects}

The investigation began with authorization from the Adventist Hospital of Belém (HAB), Brazil, Amazon region and after the approval of the research ethics committee of the Gaspar Vianna Hospital Clinic Committee (CAAE n49443615.2.0000.0016).

\section{Statistical analysis}

Fisher's Exact Test, G-Test, Student's T-Test, and Mann-Whitney Test were used to compare the characteristics of the patient groups in relation to the demographic characteristics, comorbidities, and clinical situation according to the assumptions of each test. Bioestat ${ }^{\mathbb{B}}$ 5.0 program was used for all analyses. A significance level of 5\% was used for all the work $(\mathrm{p}<0.05)$.

\section{Results}

During the study period, 284 patients with suspected sepsis were admitted, of whom 152 met the inclusion criteria. Of this sample, 30 were admitted from March to July and 122 from August to December. There were statistically significant differences higher in the case and control groups in regards to sepsis diagnosis. There were more cases of severe sepsis in the control group than in the case group (63.9\% vs. $60.0 \%$, respectively). The control group also had more cases of septic shock than the case group (36.7\% vs. 9\%, respectively) Table 2 .

Table 2 Distribution of patients diagnosed with sepsis admitted to the institution from March to December 20I5, Belém-Pará-Brazil

\begin{tabular}{lccccccc}
\hline & $\begin{array}{l}\text { Control } \\
(\mathbf{N}=30)\end{array}$ & $\begin{array}{l}\text { Case } \\
(\mathbf{N}=122)\end{array}$ & $\begin{array}{l}\text { Total } \\
(\mathbf{B}=152)\end{array}$ & P-value \\
\hline Sepsis & I & 3.3 & 33 & 27.0 & 34 & 22.4 & $<0.00 I^{\mathrm{a}}$ \\
Severe sepsis & I8 & 60.0 & 78 & 63.9 & 96 & 63.2 & \\
Septic shock & II & 36.7 & II & 9.0 & 22 & 14.5 & \\
\hline
\end{tabular}

\section{Source: Research protocol. ${ }^{\mathrm{a}} \mathrm{G}-\mathrm{Test}$.}

Regarding the general characteristics of the patients, we observed that although the groups do not contain an equal number of patients, the sample is relatively homogeneous. Females account for approximately half of the patients in both groups (control: $53.3 \%$; case: $50.0 \%$ ). There was no statistically significant difference on any of the characteristics considered between the groups Table 3. All patients who developed sepsis were diagnosed at the institution's emergency department. Regarding the place of sepsis treatment, there was a statistical difference between the groups: in the control group, $70 \%$ of the patients treated in the emergency department were transferred to the ICU, while in case group only $48.4 \%$ were transferred $(\mathrm{p}=0.041)$. In the majority of patients in both groups, the reason for hospitalization was clinical and the type of infection was community-based and pulmonary focused, with no statistical difference between them. In the evaluation of SOFA (Sequential Organ Failure Assessment), patients in the control group presented higher scores than patients in the cases group $(\mathrm{p}<0.001)$.

When analyzing the institutional performance regarding the time from organic dysfunction to the diagnosis of sepsis, there was a statistical difference between the groups studied in the emergency department. The control group had a mean of 4.4 hours and the case group has a mean of 0.5 hours $(\mathrm{p}=0.032)$. The antibiotic therapy time was also statistically different between the ICU groups, the control group with a mean of 0.9 hours and the mean of the case group 0.2 hours $(\mathrm{p}=0.020)$. 
Table 3 General characteristics of patients admitted to the institution from March to December 20I5, Belém-Pará- Brazil

\begin{tabular}{|c|c|c|c|c|c|}
\hline & \multicolumn{2}{|c|}{$\begin{array}{l}\text { Control } \\
(n=30)\end{array}$} & \multicolumn{2}{|c|}{$\begin{array}{l}\text { Case } \\
(n=\mid 22)\end{array}$} & \multirow[t]{2}{*}{ P-value } \\
\hline & $\mathbf{n}$ & $\%$ & $\mathbf{n}$ & $\%$ & \\
\hline \multicolumn{6}{|l|}{ Sex } \\
\hline Male & 14 & 46.7 & 61 & 50.0 & $0.843^{\mathrm{a}}$ \\
\hline Female & 16 & 53.3 & 61 & 50.0 & \\
\hline Age (mean $\pm S D)$ & \multicolumn{2}{|c|}{$70.9 \pm 21.9$} & \multicolumn{2}{|c|}{$71.2 \pm 18.2$} & $0.942^{b}$ \\
\hline \multicolumn{6}{|l|}{ Comorbidities } \\
\hline Alcoholism & 0 & 0.0 & 3 & 2.5 & $>0.99^{a}$ \\
\hline HIVIAIDS & 0 & 0.0 & 2 & 1.6 & $>0.99^{a}$ \\
\hline Neoplasm & 4 & 13.3 & II & 9.0 & $0.50^{\mathrm{a}}$ \\
\hline Immunosuppressants & 6 & 20.0 & 20 & 16.4 & $0.79^{a}$ \\
\hline Diabetes & 6 & 20.0 & 42 & 34.4 & $0.131^{\mathrm{a}}$ \\
\hline Heart failure & 2 & 6.7 & 13 & 10.7 & $0.743^{a}$ \\
\hline Chemotherapy & 0 & 0.0 & 3 & 2.5 & $>0.99^{a}$ \\
\hline COPD & 4 & 13.3 & 13 & 10.7 & $0.754^{\mathrm{a}}$ \\
\hline Chronic renal failure & 3 & 10.0 & 13 & 10.7 & $>0.99^{a}$ \\
\hline Radiotherapy & 0 & 0.0 & 0 & 0.0 & e \\
\hline Stroke & 3 & 10.0 & 14 & 11.5 & $>0.99^{a}$ \\
\hline Systemic arterial hypertension & 11 & 36.7 & 69 & 56.6 & $0.062^{\mathrm{a}}$ \\
\hline None & 7 & 23.3 & 17 & 13.9 & $0.265 \mathrm{a}$ \\
\hline
\end{tabular}

HIVIAIDS, Human immunodeficiency virus/human immunodeficiency syndrome. COPD, chronic obstructive pulmonary disease. HTA, systemic

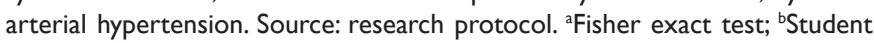
T-test.

In the analysis of the implementation of different measures proposed in the resuscitation package, no groups adhered to the complete set of measures. Meanwhile, the case group obtained greater adherence to the lactate, antibiotic, and the second lactate interventions compared to the control group. After the use of the tool, adherence to the broad-spectrum antibiotic therapy started within the first hour of the diagnosis increased from $55.5 \%$ to $81.7 \%$ in the case group ( $\mathrm{p}=0.009)$ Table 4.

Table 4 Adherence to sepsis resuscitation packages in the institution. BelémPará-Brazil.

\begin{tabular}{llllll}
\hline & \multicolumn{2}{l}{$\begin{array}{l}\text { Control } \\
(\mathbf{N = 2 7})\end{array}$} & \multicolumn{2}{l}{$\begin{array}{l}\text { Case } \\
(\mathbf{N = 9 3 ) *}\end{array}$} & P-Value $^{\mathbf{a}}$ \\
\hline Lactate & $\mathbf{n}$ & $\%$ & $\mathbf{n}$ & $\%$ & \\
Hemocultures & 17 & 63.0 & 65 & 69.9 & 0.641 \\
Antibiotics & 12 & 44.4 & 30 & 32.2 & 0.263 \\
Volume/Glass & 15 & 55.5 & 76 & 81.7 & 0.011 \\
Collection of 2 & $7 / 7$ & 100.0 & $7 / 8$ & 87.5 & $>0.99$ \\
Reassessment & $1 / 2$ & 50.0 & $6 / 7$ & 85.7 & 0.424 \\
\hline
\end{tabular}

*Patients who were adherent to the measures. ${ }^{\text {a }}$ isher exact test.
The measurement of hospitalization time from admission to discharge showed a statistical difference between the groups. Surviving patients in the control group had a mean of $19.7 \pm 10.3$ days and the mean in the cases group was $7.7 \pm 11.9$ days $(\mathrm{p}=0.001)$. In the evaluation of the mortality of patients with sepsis, we noticed a statistical difference between the groups, with a rate of $30.6 \%$ in the case group compared to a rate of $63.3 \%$ in the control group $(\mathrm{p}=0.001)$ Figure 1.

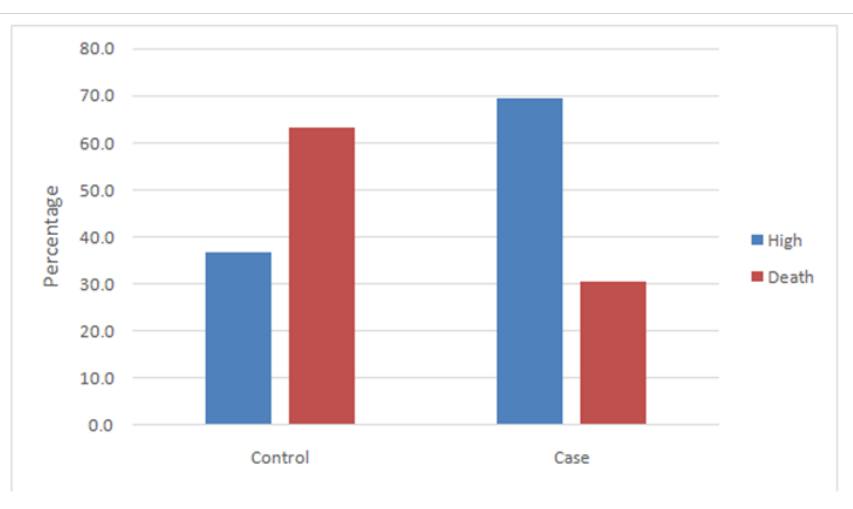

Figure I Lethality of patients admitted to the institution with a diagnosis of sepsis. Belém-Pará - Brazil.

*P value for Fisher exact test $=0.0014$.

* High risk

\section{Discussion}

It has been 14 years since CSS was first launched, when a group of professionals joined the challenge of developing recommendations to improve care, based on good medical practice, with the goal of reducing mortality by $25 \%$ in patients with sepsis. However, the incidence of this disease remains high and institutions find great difficulties in adoption and implementation of these protocols because the clinical management of sepsis is so complex. ${ }^{17-20}$

The present study revealed a high incidence of severe sepsis (63.2\%) among patients diagnosed with sepsis. A high frequency of severe sepsis $(74.9 \%)$ was also found in a study performed at the ICU of a Recife hospital, which shows the severity of this pathology. ${ }^{21}$ After the implementation of the educational tool, a significant difference was observed in the number of patients diagnosed with sepsis without dysfunction $(p<0.001)$. Early diagnosis is crucial considering that when treating this disease its initial development is less severe and its advance may be prevented with treatment. This may reveal that the improvement in knowledge and practical skills has led to increased sensitivity in recognition of this type of patient after an intervention measure. $^{22,23}$

In this study, there was no association between the presence of sepsis, gender, and comorbidities, consistent with another study performed in a public hospital in the same region. ${ }^{24}$ However, it is worth noting that the prevalence of sepsis, according to gender and comorbidities, differs according to the sample and the study. ${ }^{21,25,26}$ The place of diagnosis and initiation of measures to combat sepsis occurs mainly in the emergency department. ${ }^{18,27}$ It is important to emphasize that the transfer of patients to the ICU was lower in the case group, which shows that the use of an educational tool and the implementation and execution of a protocol may decrease a patient's severity of illness due to the initial handling of the disease..$^{10,22,23}$ The most frequent reason for hospitalization was clinical, with a predominance of community 
infection, with pulmonary focus prevailing in both groups. Studies conducted in different regions confirm this distribution. ${ }^{18,21,27,28}$

The literature suggests that there is a strong relationship between the time between organic dysfunction and the diagnosis of sepsis, as well as the time between antibiotic administration and mortality. ${ }^{29}$ After the intervention, it was observed that providers in the emergency department made an earlier diagnosis of sepsis, with only 30 minutes from the time of dysfunction until the diagnosis; in the ICU, the time of administration of antibiotics reached approximately 12 minutes. After the educational intervention, there was no increase in adherence to the measures in their entirety, but a better appreciation of the individual components, as other studies show. ${ }^{10}$

The use of antibiotic therapy was significantly higher after the use of the tool, increasing from $55.5 \%$ to $81.7 \%(\mathrm{p}=0.009)$. Studies have shown that the administration of antibiotics should be immediate and be a top priority goal in the care of septic patients, trying to minimize bacterial load. ${ }^{30,31}$ Each hour of delay in antibiotic therapy is associated with an increase in mortality. However, it is important to note that antibiotic therapy, initiated before blood culture, delays or prevents the detection of the microorganisms responsible for the infection, which is generally positive in $30 \%$ to $50 \%$ of patients with sepsis. That is why it is important to emphasize the "time" factor in the different areas of focus in continuing education. Better coordination between those who diagnose the disease (laboratory) and those who administer the drugs (pharmacy) is crucial, so that the early administration of antibiotics does not hinder the results of blood cultures.

Regarding the lactate measurement, no significant improvement in adherence to the protocol was found. However, it is worth emphasizing a tendency in the improvement of adherence. This is important since the increased lactate value reflects a state of tissue hypoperfusion, which facilitates the diagnosis of subclinical shock, allowing early and adequate administration of intravenous fluids, increasing the survival rate of these patients. An increased lactate level is associated with a worse prognosis, which is why a smaller percentage of patients developed septic shock after the use of the tool $(9 \%){ }^{32,33}$

The average length of stay for patients with sepsis was consistent with previous studies, ranging from 15.3-18.4 days. ${ }^{34}$ In another study, the average length of stay before the introduction of the CSS resuscitation packages was 10.5 days in the United States and 22.8 days in Europe. ${ }^{35}$ In this study, after the educational tool was introduced, the average length of stay was 7.7 days, which reflects the benefit for both the patient and the hospital, since shorter stays lead to a decreased costs. ${ }^{36}$

In this study, the identification and early treatment by the use of the training strategy for patients with sepsis allowed a reduction in mortality to $30.6 \%$, a result lower than that found in a cohort in Europe. ${ }^{4}$ This study on quality indicators in sepsis treatment has shown that training strategies may motivate professionals to search for and continuously improve their knowledge and ability to solve different situations they face, thus improving the outcomes of patients with sepsis. ${ }^{37}$

\section{Conclusion}

Sepsis is a disease that requires exhaustive and multidisciplinary research. Although it is difficult to adopt and implement a care protocol and apply improvement strategies, it is still the best way to achieve greater adherence and improve patient prognosis. After implementation of the tool, the mortality rate for patients with sepsis was lower and their hospital stays were shorter. Additionally, there was a marked decrease in the transfer of patients with sepsis to the ICU, institutional performance in the detection of the first organ dysfunction increased, and the initial administration of antibiotics improved.

\section{Acknowledgements}

None.

\section{Conflict of interest}

The author declares no conflict of interest.

\section{References}

1. Dellinger RP, Levy MM, Rhodes A, et al. Surviving sepsis campaign: international guidelines for management of severe sepsis and septic shock: 2012. Crit Care Med. 2013;41(1):580-637.

2. Martin JB, Wheeler AP. Approach to the patient with sepsis. Clin Chest Med. 2009;30(1):1-16.

3. Gaieski DF, Edwards JM, Kallan MJ, et al. Benchmarking the incidence and mortality of severe sepsis in the united states. Crit Care Med. 2013;41(5):1167-1174.

4. Levy MM, Artigas A, Phillips GS, et al. Outcomes of the surviving sepsis campaign in intensive care units in the USA and Europe: a prospective cohort study. Lancet Infect Dis. 2012;12(12):919-924.

5. Kauss IAM, Grion CMC, Cardoso LTQ, et al. The epidemiology of sepsis in a Brazilian teaching hospital. Braz J Infect Dis. 2010;14(3):264-270.

6. Flavia R Machado, Fernanda Carrara, Alexandre C Biasi, et al. Estudo revela que Brasil ainda tem alta prevalência de mortalidade por sepse em todas as regiões do país. Brazile: Springer; 2014.

7. Romero C, Hernández G. Initial resuscitation bundle and monitoring tissue perfusion in severe sepsis. Rev Med Chil. 2013;141(9):1173-1181.

8. Mayr FB, Yende S, Angus DC. Epidemiology of severe sepsis. Virulence. 2014;5(1):4-11.

9. Instituto Latino Americano da Sepse. Brazile.

10. Pérez AL, Rosell EC, Lacosta MD, et al. (2012) Clinical pathway intervention compliance and effectiveness when used in the treatment of patients with severe sepsis and septic shock at an Intensive Care Unit in Spain. Rev Lat Am Enfermagem 20(4): 635-643.

11. Espichán MM. Strategies for improving survival in patients with severe sepsis. Acta Médica Peruana. 2010;27(4):302-309.

12. Rocha LL, Pessoa CMS, Corrêa TD, et al. Current concepts on hemodynamic support and therapy in septic shock. Revista Brasileira de Anestesiologia. 2015;65(5):395-402.

13. Bruhn AC, Pairumani RM, Hernandez GP. Manejo del paciente, en shock séptico. Revista Médica Clínica Las Condes. 201;22(3):293-301.

14. Romero CP, Cornejo RR, Tobar EA, et al. Reanimación protocolizada del shock séptico. Revista HCUCH. 2008;19:127-141.

15. Hernández G, Bruhn A, Castro R, et al. The holistic view on perfusion monitoring in septic shock. Curr Opin Crit Car. 2012;18(3):280-286.

16. Comitê Científico do Programa Brasileiro de Segurança do PacientePBSP.

17. Vicente M. Escalas pronósticas en la Unidad de Terapia Intensiva. 
Revista de Medicina Crítica y Terapia Intensiva. 2012;26(4):234-241.

18. Rhodes A, Phillips G, Beale R, et al. The Surviving Sepsis Campaign bundles and outcome: results from the International Multicentre Prevalence Study on Sepsis (the IMPreSS study). Intensive Care Med. 2015;41(9):1620-1628.

19. Vásquez AL, Gil CL, Regidor AL. New therapeutic alternatives for severe sepsis in the critical patient. A review. Med Intensiva. 2011;35(4):236245 .

20. Quintero RA, Martínez CA, Gamba JD, et al. Adherence to international guidelines on early management in severe sepsis and septic shock. Biomedica. 2012;32(3):449-456.

21. Koury JCA, Lacerda HR, Barros AJN. Characteristics of septic patients in an intensive care unit of a tertiary private hospital from Recife, northeast of Brazil. Rev Bras Ter Intensiva. 2006;18(1):52-58.

22. Armero EG, Yébenes JCR, Vendrell MJB. Implementación de una estrategia en formato código para mejorar el manejo de la sepsis grave comunitaria en hospitales comarcales sin UCI. Universidad Autónoma de Barcelona; 2014.

23. Girardis M, Rinaldi L, Donno L. Effects on management and outcome of severe sepsis and septic shock patients admitted to the intensive care unit after implementation of a sepsis program: a pilot study. Crit Care. 2009;13(5):R143.

24. Silva AQ, Sobrinho EB. Análise de medidas de combate a sepse em Unidade de Terapia Intensiva. Hospital de Clínicas Gaspar Vianna; 2015.

25. Ponce JIL, Vilcapoma FV. Características clínicas de los pacientes con sepsis severa admitidos a una unidad de cuidados intensivos. Revista Peruana de Medicina Interna. 2008;21(4):139-142.

26. Yoshihara JC, Okamoto TY, Queiroz LT. Análise descritiva dos pacientes com sepse grave ou choque séptico e fatores de risco para mortalidade. Semina: Ciências Biológicas e da Saúde. 2011;32(2):127-134.

27. Peake SL, Delaney A, Bailey M, et al. Goal-directed resuscitation for patients with early septic shock. NEngl J Med.2014;371(16):1496-1506.

28. Zanon F, Caovilla JJ, Michel RS, et al. Sepse na Unidade de Terapia Intensiva: Etiologias, Fatores Prognósticos e Mortalidade. Revista Brasileira de Terapia Intensiva. 2008;20(2):128-134.

29. Características clínicas y factores de riesgo para moralidad en pacientes sépticos internados en cuidados intensivos de hospitales públicos y privados brasileños.

30. Bloos F, Rüddel DT, Rüddel H, et al. Impact of compliance with infection management guidelines on outcome in patients with severe sepsis: a prospective observational multi-center study. Critical Care. 2014;18(2):R42.

31. Tejedo A, Pazos E, Peters S, et al. Implementación de un "Código Sepsis Grave” en un servicio de urgencias. Emergencias. 2009;21:255-261.

32. Rivers E, Nguyen HB. Early Goal-Directed Therapy in the treatment of severe sepsis and septic shock. N Engl J Med. 2001;345(19):1368-1377.

33. Zapata LMM, Jaimes FB. Fisiopatología, importancia y utilidad del lactato en pacientes con sepsis. IATREIA. 2010;23(3):278-285.

34. Clèries M. Epidemiologia de la Sèpsia Greu a Catalunya. Jornada tècnica sobre el Continu Assistencial en el Maneig de la Sèpsia Greu.

35. Koenig A, Picon PD, Feijó J, et al. Estimativa do impacto econômico da implantação de um protocolo hospitalar para detecção e tratamento precoce de sepse grave em hospitais públicos e privados do sul do Brasil. Revista Brasileira de Terapia Intensiva. 2010;22(3):213-219.

36. Román IP, Varela AIC, Pérez WQ, et al. Sepsis: a strategy of training in Primary Health Care and hospital emergencies. Indicators of quality in the care of patients. Revista de Ciencias Médicas de Pinar del Río. 2012;16(3):120-138.

37. Salazar N, Griñen H, Jirón M, et al. Impacto del cuidado Multidisciplinario en los desenlaces clínicos de los pacientes críticos. Revista Chilena de Medicina Intensiva. 2012;27(1):15-22. 